\title{
Adhesion of Vibrios and Aeromonads to Isolated Rabbit Brush Borders
}

\author{
By P. N. LEVETT*† AND R. R. DANIEL \\ Department of Microbiology, University of Surrey, Guildford GU2 $5 X H, U . K$.
}

(Received 29 September 1980; revised 13 January 1981)

Isolated rabbit brush borders were used to investigate the adhesive properties of clinical and environmental isolates of non-O1 Vibrio cholerae and clinical isolates of Vibrio parahaemolyticus and Aeromonas hydrophila. A minority of the isolates were found to adhere to brush borders. The adhesion of these isolates was affected by a number of factors, including the bacteria:brush border ratio, incubation time, culture medium and growth temperature. Adhesion was inhibited by L-fucose but was independent of calcium ion concentration.

\section{INTRODUCTION}

Adhesion of Vibrio cholerae to the intestinal mucosa appears to play a role in the pathogenesis of cholera (Srivastava et al., 1980). A number of in vitro models for the investigation of adhesion of enterotoxigenic bacteria to the mucosal surface have been described, including the use of tissue segments (Freter, 1969), isolated enterocytes (Jones, 1972) and isolated brush borders (Sellwood et al., 1975).

Non-O1 V. cholerae, previously regarded as non-pathogenic environmental organisms, may also cause diarrhoea by a mechanism similar to that of $V$. cholerae serovar O1 (Ohashi et al., 1972). A similar mechanism has been proposed in the pathogenesis of diarrhoea caused by Aeromonas hydrophila (Sanyal et al., 1975). No studies have examined the adhesive properties of non-O1 V. cholerae, but the adhesion of $V$. cholerae $\mathrm{O} 1$ to isolated rabbit brush borders has been reported (Jones et al., 1976). A recent comparison of the pathogenicity of clinical and environmental isolates of $V$. cholerae $\mathrm{O} 1$ did not encompass adhesive ability (Sigel et al., 1980). The adhesion of $V$. parahaemolyticus to human tissue culture cells has been described: Carruthers (1977) found a correlation between adhesion to HeLa cells and production of the Kanagawa haemolysin, whereas Gingras \& Howard (1980) found no significant difference in adherence of Kanagawa-positive and Kanagawa-negative strains to human epithelial cell lines.

In view of the absence of data on adhesion of non-O1 V. cholerae and $A$. hydrophila, the rabbit brush border assay was used to investigate the adhesion of clinical and environmental isolates of non-O1 V. cholerae, and clinical isolates of $A$. hydrophila and $V$. parahaemolyticus.

\section{METHODS}

Bacteria. Eighteen strains of non-O1 Vibrio cholerae (NCV), four strains of Vibrio parahaemolyticus and five strains of Aeromonas hydrophila were isolated from stools of patients suffering acute diarrhoeal disease. In addition, eighteen strains of $A$. hydrophila isolated from faeces were received from Miss $\mathrm{N}$. Sodha of the Tooting Public Health Laboratory. Twenty-two NCV strains isolated from environmental sources were received from Dr J, V. Lee of the Maidstone Public Health Laboratory. U.K.

$\dagger$ Present address: Public Health Laboratory, Luton and Dunstable Hospital, Lewsey Road, Luton LU4 0DZ, 
Media. All the isolates studied were maintained on slopes of nutrient agar (Oxoid) containing $1 \%(\mathrm{w} / \mathrm{v}) \mathrm{NaCl}$ (salt nutrient agar). Organisms to be tested were cultured statically in nutrient broth (Oxoid) containing $1 \%$ (w/v) $\mathrm{NaCl}$ (salt nutrient broth) for $16 \mathrm{~h}$ at $37^{\circ} \mathrm{C}$. After incubation, cultures were centrifuged at $2000 \mathrm{~g}$ for $25 \mathrm{~min}$, washed twice in Krebs-Henseleit $(\mathrm{KH})$ buffer (Sellwood et al., 1975) and resuspended in $\mathrm{KH}$ buffer to a concentration of approximately $5 \times 10^{8}$ colony-forming units (c.f.u.) $\mathrm{ml}^{-1}$.

Preparation of rabbit brush borders. Brush borders were prepared from the small intestine of rabbits by the method described by Sellwood et al. (1975). The brush borders were stored at $4{ }^{\circ} \mathrm{C}$ in $5 \mathrm{~mm}$-EDTA containing $10 \%(\mathrm{v} / \mathrm{v})$ formalin, and their suitability for use was determined by performing the adhesion assay using a number of control strains. If a significant variation in adhesion index occurred the brush borders were discarded and a fresh preparation was made. Brush borders were washed twice in $\mathrm{KH}$ buffer before use, and resuspended in $\mathrm{KH}$ buffer to a concentration of approximately $10^{6}$ brush borders $\mathrm{ml}^{-1}$.

Brush border adhesion assay. Equal volumes $(0.1 \mathrm{ml})$ of brush border and bacterial suspensions were mixed in $0.5 \mathrm{ml}$ micro-centrifuge tubes and incubated at $37^{\circ} \mathrm{C}$ for $15 \mathrm{~min}$ with continuous gentle mixing. One drop of the test mixture was examined by phase contrast microscopy, and the number of bacteria adhering to each of 20 brush borders was counted. Each test was duplicated, and all organisms were tested three times. The adhesion index was thus determined as the mean number of bacteria adhering to each of 120 brush borders. Mean adhesion indices were compared by the Fisher-Behren's d-test (Snedecor \& Cochran, 1967).

\section{RESULTS}

\section{Adhesion to rabbit brush borders}

Bacteria were seen to adhere to the micro-villous surfaces of brush borders. This property was exhibited by isolates of all three species examined. The maximum number of bacteria which could be accurately counted was 30 , thus the maximum value of the adhesion index was 30 , although some isolates adhered in numbers greater than this. It was noted that a small proportion of the brush borders in any preparation did not support the adhesion of bacteria. Organisms with an adhesion index of 5 or less were regarded as non-adhesive; a clear distinction was observed between these isolates and those having an adhesion index of 20 or greater, which were regarded as strongly adhesive.

The adhesion indices of the 67 strains studied are summarized in Table 1. The adhesion indices of 18 clinical NCV isolates ranged from 0.2 to 29.5 bacteria per brush border. Using the above criteria, 13 clinical NCV isolates were regarded as non-adhesive. The mean adhesion index of the non-adhesive isolates was $1 \cdot 1( \pm 1 \cdot 3)$, while that of the 5 adhesive NCV isolates was $20.6( \pm 7.8)$. The difference in mean values was considered highly significant $(z=5 \cdot 56)$.

The adhesion indices of the $V$. parahaemolyticus isolates ranged from 3.9 to 29.3 . Three isolates were considered adhesive; the mean adhesion index of these isolates was $28.6( \pm 1 \cdot 0)$. The difference between this value and the corresponding value for the adhesive NCV isolates was significant (at the 0.05 level but not at the 0.01 level; $z=2.26$ ).

The adhesion indices of 22 environmental NCV isolates ranged from 0.1 to 30 . Seven isolates were considered to be adhesive, their mean adhesion index being $17 \cdot 4( \pm 9.4)$. The difference between the mean adhesion indices of adhesive environmental and clinical NCV isolates was not significant $(z=0 \cdot 64)$.

Only 4 of the 23 clinical $A$. hydrophila were considered adhesive, their mean adhesion index being $9.9( \pm 5.4)$; this was significantly different from that of the adhesive NCV isolates (at the 0.05 level; $z=2.42$ ).

\section{Effect of test and cultural conditions on adhesion index}

Using selected strains, various test and cultural conditions were investigated as possible sources of the observed variation in adhesion indices.

The adhesion indices of a clinical NCV strain (154) and of a $V$. parahaemolyticus strain (40) were dependent on the bacterial concentration, and thus on the ratio of bacteria to brush borders (Fig. 1). 
Table 1. Summary of adhesive properties of the 67 strains studied

\begin{tabular}{|c|c|c|c|c|}
\hline \multirow[b]{2}{*}{ Organism } & \multirow{2}{*}{$\begin{array}{l}\text { No. of } \\
\text { strains }\end{array}$} & \multirow[b]{2}{*}{ Source } & \multicolumn{2}{|c|}{$\begin{array}{l}\text { No. of strains with } \\
\text { adhesion indices of: }\end{array}$} \\
\hline & & & $<5$ & $5-30$ \\
\hline Non-O1 $V$. cholerae & 18 & Clinical & 13 & 5 \\
\hline Non-01 $V$. cholerae & 22 & Environmental & 15 & 7 \\
\hline V.parahaemolyticus & 4 & Clinical & 1 & 3 \\
\hline A. hydrophila & 23 & Clinical & 19 & 4 \\
\hline
\end{tabular}

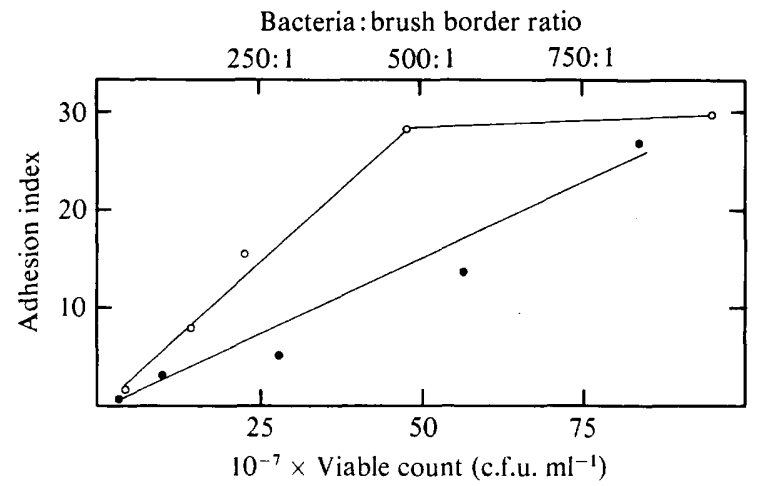

Fig. 1. Effect of bacterial concentration on adhesion index. The bacterial concentration used in the brush border assay $\left(5 \times 10^{8}\right.$ c.f.u. $\left.\mathrm{ml}^{-1}\right)$ gave the greatest separation between a strongly adhesive strain ( . parahaemolyticus strain $40 ; O$ ), and a moderately adhesive strain (NCV strain 154;

\section{Table 2. Effect of test and cultural conditions on adhesion index}

Species (strain)

Source

Standard test Incubation time ( $\mathrm{min})$

5
15
30
45
60

L-Fucose concn $\left(\mu \mathrm{g} \mathrm{ml}^{-1}\right)$

$$
10
$$$$
100
$$

Growth temp. $\left({ }^{\circ} \mathrm{C}\right)$

$\begin{array}{lr}20 & 0.4( \pm 0.7) \\ 25 & 2.8( \pm 2.3) \\ 30 & 21.2( \pm 10.9) \\ 37 & 28.2( \pm 5.4) \\ 40 & 3.8( \pm 3.3) \\ \text { Culture medium* } & \\ \text { SNB } & \\ \text { SNA } & 29.1( \pm 2.8) \\ \text { BA } & 0.2( \pm 0.5) \\ & 0.4( \pm 0.8)\end{array}$

$V$. parahaemolyticus $(40)$

Clinical

$29 \cdot 3( \pm 3 \cdot 0)$

$$
\begin{array}{r}
8.7( \pm 3.6) \\
29.0( \pm 4.4) \\
23 \cdot 5( \pm 10 \cdot 2) \\
6.0( \pm 5.4) \\
6.5( \pm 6.2)
\end{array}
$$

$27 \cdot 9( \pm 5 \cdot 2)$
$10 \cdot 4( \pm 7 \cdot 2)$

$0.4(+0.8)$

Values shown are the mean adhesion indices \pm S.D.

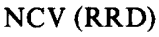

Environmental

$30(0)$

$$
\begin{array}{r}
6.8( \pm 5 \cdot 1) \\
29 \cdot 7( \pm 3 \cdot 1) \\
14 \cdot 2( \pm 4 \cdot 8) \\
11.4( \pm 5 \cdot 7) \\
3.9( \pm 2 \cdot 4)
\end{array}
$$

$$
\begin{aligned}
& 30 \quad(0) \\
& 14 \cdot 7( \pm 5 \cdot 4)
\end{aligned}
$$

$3 \cdot 5( \pm 2 \cdot 1)$

$29.6( \pm 3 \cdot 5)$

$30 \quad(0)$

$30 \quad(0)$

$0.4( \pm 1.2)$

NCV (27958)

NCV (85)

Clinical

$27.0( \pm 6.4)$

$6 \cdot 5(+5 \cdot 3)$

$27 \cdot 9( \pm 3 \cdot 1)$

$21.3( \pm 9.4)$

$4.7( \pm 3.6)$

$2 \cdot 3( \pm 2 \cdot 1)$

$28 \cdot 6( \pm 6 \cdot 7)$

$13 \cdot 2( \pm 3 \cdot 9)$

$5 \cdot 2( \pm 2 \cdot 9)$

$16 \cdot 1( \pm 8 \cdot 3)$

$23 \cdot 8( \pm 8 \cdot 6)$

$30 \quad(0)$

$0.6( \pm 0.6)$
$30 \quad(0)$
$1 \cdot 0( \pm 1 \cdot 3)$
$0.4( \pm 1.5)$

$28 \cdot 3( \pm 5 \cdot 4)$

$1 \cdot 1( \pm 1 \cdot 4)$

$0.7( \pm 1.6)$
Clinical

$0.4( \pm 0.8)$

$0.1( \pm 0.2)$

$0.9( \pm 0.8)$

$0.6(+0.9)$

$0.3( \pm 0.4)$

$0.4( \pm 0.4)$

$0.4( \pm 0.8)$

$0.5( \pm 1.0)$

$0 \cdot 2( \pm 0 \cdot 3)$

$0 \cdot 1( \pm 0.4)$

$0.5( \pm 0.5)$

$1 \cdot 0( \pm 1 \cdot 1)$

$0.2( \pm 0.5)$

$0.6( \pm 1.0)$

$0.5( \pm 0.9)$

$0.4( \pm 0.8)$

* SNB, Salt nutrient broth; SNA, salt nutrient agar; BA, blood agar. 
Maximum adhesion of three adhesive isolates (clinical and environmental NCV isolates and a strain of $V$. parahaemolyticus) occurred after $15 \mathrm{~min}$ incubation, followed by a decline in adhesion index (Table 2). The adhesion indices of these strains were significantly reduced after $45 \mathrm{~min}$ incubation. Incubation time had no effect on the adhesion index of a non-adhesive NCV strain (85).

Adhesion of three of the strains above was inhibited by L-fucose (Sigma) at a concentration of $100 \mu \mathrm{g} \mathrm{ml}^{-1}$ but not $10 \mu \mathrm{g} \mathrm{ml}^{-1}$ (Table 2). Neither concentration affected the adhesion of the non-adhesive isolate (85).

Two NCV isolates (RRD and 27958) were strongly adhesive when grown at 25, 30 and $37^{\circ} \mathrm{C}$, but non-adhesive when grown at 20 and $40^{\circ} \mathrm{C}$ (Table 2). The isolate of $\mathrm{V}$. parahaemolyticus (40) was strongly adhesive when grown at 30 and $37^{\circ} \mathrm{C}$, but non-adhesive when grown at 20,25 and $40^{\circ} \mathrm{C}$. Growth temperature had no effect on the adhesion of the non-adhesive NCV strain (85).

Three strains (RRD, 27958 and 40) were adhesive when cultured in salt nutrient broth but not when cultured on salt nutrient agar or blood agar (Table 2). Culture medium had no effect on the adhesion of the non-adhesive NCV strain (85).

To test the observation that adhesion of $V$. cholerae to rabbit brush borders required the presence of calcium ions (Jones et al., 1976), the assay was performed using buffer containing $1.8 \mathrm{mM}^{-\mathrm{CaCl}_{2}}$. The presence of calcium ions at this concentration had no effect on the adhesion indices of the isolates examined (thirteen clinical NCV isolates, two $V$. parahaemolyticus, one environmental NCV isolate and one $A$. hydrophila isolate).

\section{DISCUSSION}

The results presented confirm the presence of an adhesive factor (adhesin) in some isolates of non-O1 $V$. cholerae, $V$. parahaemolyticus and $A$. hydrophila, which mediates adhesion to a receptor site located on rabbit brush borders. However, the majority of the isolates examined lacked this adhesin. The proportion of clinical and environmental NCV isolates exhibiting adhesion was approximately equal. The ability to adhere has ecological benefits both for pathogens and environmental organisms. Adhesion in the natural environment enhances bacterial activity (ZoBell, 1943) while adhesion to gut mucosa facilitates colonization. Rabbit brush border membranes possess a receptor(s) which bind the adhesin(s) of environmental $\mathrm{NCV}$ isolates in addition to those of clinical isolates. However, the relevance of this finding to adherence in the natural environment is unknown.

Expression of the adhesive factors was markedly affected by test and cultural conditions. Similar findings were reported for $V$. cholerae $O 1$ by Jones et al. (1976) and for $V$. parahaemolyticus by Carruthers (1977) and Carruthers \& Anderson (1979). In addition, the adhesive factors of non-O1 $\mathrm{V}$. cholerae were expressed only over a limited growth temperature range. An environmental NCV isolate (RRD) adhered equally strongly when grown at 25,30 and $37^{\circ} \mathrm{C}$, while the clinical NCV isolate (27958) was considered more adhesive when grown at 30 and $37^{\circ} \mathrm{C}$ than at $25^{\circ} \mathrm{C}$. Like $V$. cholerae $\mathrm{O} 1$ (Jones \& Freter, 1976) the adhesion of NCV isolates was fucose-sensitive. At a fucose concentration of $100 \mu \mathrm{g} \mathrm{ml}^{-1}$ the adhesion of three strains was significantly reduced.

Adhesion of the strains studied was not calcium-dependent, in contrast to the findings of Jones et al. (1976) for $V$. cholerae O1. Guentzel et al. (1978) reported that strains of $V$. cholerae $\mathrm{O} 1$ exhibited a variable requirement for calcium ions. Isolates of $V$. parahaemolyticus studied by Carruthers \& Anderson (1979) also required calcium ions for adhesion to occur. The mechanism by which calcium ions may or may not enhance adhesion is unknown. It has been suggested that differences in surface structure between bacterial strains may affect surface charge and account for the variations observed in adhesive ability between strains of the same species (Carruthers \& Anderson, 1979). This may also explain the variable effect of cations on adhesion. 
Adhesion clearly depends on the model system employed and on cultural conditions. Observations made from the study of adhesion in several models strongly suggest that multiple adhesive mechanisms may operate in $V$. cholerae O1 (Jones, 1980). A similar situation appears to occur in non-O1 $V$. cholerae.

The nature of the adhesin(s) produced by vibrios is unclear. A soluble haemagglutinin (cholera lectin) was isolated from $V$. cholerae O1 (Finkelstein et al., 1978). Some Vibrio species bear fimbriae which mediate mannose-sensitive haemagglutination (Tweedy et al., 1968). Fimbrial surface antigens mediate mannose-resistant adhesion of many enterotoxigenic Escherichia coli strains to intestinal mucosa. However, Nelson et al. (1976) could not demonstrate such fimbriae in $V$. cholerae $\mathrm{O} 1$ by electron microscopy. Lankford \& Legsomburana (1965) proposed that adhesion of $V$. cholerae to the intestinal mucosa is mediated by the cell surface.

In view of the variation in adhesive properties detected between different model systems, it is quite probable that several adhesive structures may occur in non-O1 $\mathrm{V}$. cholerae, their expression being dependent on a range of conditions. Further investigations are necessary to elucidate the nature of individual adhesive mechanisms.

Part of this work formed the basis of a report submitted by P.N.L. in partial fulfilment of the requirements for the B.Sc.(Hons) degree of the University of Surrey. P.N.L. acknowledges the support of a scholarship awarded by the Metal Box Co. Ltd; R.R.D. was supported by a Wellcome Trust studentship.

\section{REFERENCES}

CARruthers, M. M. (1977). In vitro adherence of Kanagawa-positive Vibrio parahaemolyticus to epithelial cells. Journal of Infectious Diseases 136, 588-592.

Carruthers, M. M. \& Anderson, B. (1979). Inhibition by polyanions of adherence of Kanagawapositive Vibrio parahaemolyticus: a physicochemical effect. Journal of Infectious Diseases 140, 119-122.

Finkelstein, R. A., Arita, M., Clements, J. D. \& NeLson, E. T. (1978). Isolation and purification of an adhesive factor ('cholera lectin') from Vibrio cholerae. In Proceedings of the 13th Joint Conference on Cholera, the U.S.-Japan Cooperative Medical Science Program, pp. 137-147. Washington, D.C.: U.S. Govt. Printing Office.

FreTER, R. (1969). Studies of the mechanisms of action of intestinal antibody in experimental cholera. Texas Reports on Biology and Medicine 27, 299316.

Gingras, S. P. \& Howard, L. V. (1980). Adherence of Vibrio parahaemolyticus to human epithelial cell lines. Applied and Environmental Microbiology 39, 369-371.

Guentzel, M. N., Jocz, R. J., Wong, G. G., GAY, T. V. \& Guerrero, D. L. (1978). Vibrio cholerae adhesion. In Abstracts of the Annual Meeting of the American Society for Microbiology, p. 14. Washington, D.C.: American Society for Microbiology.

JONES, G. W. (1972). The adhesive properties of $K 88$ antigen of strains of Escherichia coli pathogenic to neonatal pigs. Ph.D. thesis, University of Reading, U.K.

JONES, G. W. (1980). The adhesive properties of Vibrio cholerae and other Vibrio species. In Bacterial Adherence, pp. 219-249. Edited by E. H. Beachey. London: Chapman and Hall.
Jones, G. W. \& Freter, R. (1976). Adhesive properties of Vibrio cholerae: nature of the interaction with isolated rabbit brush border membranes and human erythrocytes. Infection and Immunity 14, 240-245.

Jones, G. W., Abrams, G. D. \& Freter, R. (1976). Adhesive properties of Vibrio cholerae: adhesion to isolated rabbit brush border membranes and hemagglutinating activity. Infection and Immunity 14, 232-239.

LANkFord, C. E. \& Legsomburana, U. (1965). Virulence factors of choleragenic vibrios. In Proceedings of the Cholera Research Symposium, pp. 109-120. Edited by O. H. Bushnell \& C. S. Brookhyser. Washington, D.C.: U.S. Govt. Printing Office.

Nelson, E. T., Clements, J. D. \& Finkelstein, R. A. (1976). Vibrio cholerae adherence and colonization in experimental cholera: electron microscopic studies. Infection and Immunity 14, 527-547.

Ohashi, M., Shimada, T. \& Fukumi, H. (1972). In vitro production of enterotoxin and hemorrhagic principle by Vibrio cholerae, NAG. Japanese Journal of Medical Science and Biology 25, 179-194.

Sanyal, S. C., Singh, S. J. \& Sen, P. C. (1975). Enteropathogenicity of Aeromonas hydrophila and Plesiomonas shigelloides. Journal of Medical Microbiology 8, 195-198.

Sellwood, R., Gibbons, R. A., Jones, G. W. \& RutTer, J. M. (1975). Adhesion of enteropathogenic Escherichia coli to pig intestinal brush borders: the existence of two pig phenotypes. Journal of Medical Microbiology 8, 405-411.

Sigel, S. P., LANier, S., BASElSki, V. S. \& Parker, C. D. (1980). In vivo evaluation of pathogenicity of clinical and environmental isolates of Vibrio cholerae. Infection and Immunity 28, 681-687. 
Snedecor, G. W. \& Cochran, W. G. (1967). Tweedy, J. M., Park, R. W. A. \& Hodgkiss, W. Statistical Methods, 6th edn. Iowa State University (1968). Evidence for the presence of fimbriae (pili) Press.

Srivastava, R., Sinha, V. B. \& Srivastava, B. S. (1980). Events in the pathogenesis of experimental cholera: role of bacterial adherence and multiplication. Journal of Medical Microbiology 13, 1-9. on vibrio species. Journal of General Microbiology $51,235-244$.

ZoBeLL, C. E. (1943). The effect of solid surfaces upon bacterial activity. Journal of Bacteriology 46, 39-59. 